\title{
High Efficiency Dilute Nitride Solar Cells: Simulations Meet Experiments
}

\author{
A. Tukiainen*, A. Aho, V. Polojärvi, R. Ahorinta and M. Guina \\ Optoelectronics Research Centre, Tampere University of Technology, \\ Korkeakoulunkatu 3, FI-33720 Tampere, Finland \\ *Corresponding Author: antti.tukiainen@tut.fi
}

Received 5 November 2015; Accepted 3 June 2016;

Publication 1 August 2016

\begin{abstract}
Parameter extraction procedure and simulation of dilute nitride solar cells are reported. Using PC1D simulation and fitting to experimental current-voltage and external quantum efficiency data, we retrieve the phenomenological material parameters for GaInNAs solar cells. Based on these, we have constructed a model that can explain the changes in short circuit current and open circuit voltage of $n-i-p$ solar cells subjected to rapid thermal annealing. The model reveals that non-annealed MBE-grown GaInNAs material has an $\mathrm{n}$-type doping that evolves to $\mathrm{p}$-type upon rapid thermal annealing. The change of doping type and the shift of the physical location of the pn-junction were confirmed by Kelvin-probe force microscopy. The PC1D modelling was found to work well also for GaInNAs p-i-n solar cells with opposite polarity. It was also found that the GaInNAs lower doping levels in p-i-n solar cells grown at lowered As/III flux ratios were associated with increased carrier lifetimes.
\end{abstract}

\section{Introduction}

Recently, dilute nitride materials, i.e. GaInNAs-based semiconductors, have drawn increased attention in the photovoltaics research community. This is due to their ability to increase the efficiency of solar cells used in terrestrial concentrator photovoltaics and space power systems [1,2]. The use of $1 \mathrm{eV}$

Journal of Green Engineering, Vol. 5, 113-132.

doi: 10.13052/jge 1904-4720.5348

(C) 2016 River Publishers. All rights reserved. 


\section{A. Tukiainen et al.}

dilute nitride sub-junctions have been actively studied both experimentally and theoretically [1,3-7]. Although the potential of this approach has been validated experimentally [2], the connection between experimental results and simulation, in particular the reliable parameter extraction, has remained elusive. Here, we present a study for the simulation of single junction dilute nitride solar cells and extraction of useful physical parameters that can be used for simulation of high efficiency multi-junction cells. The effects of thermal annealing are also discussed.

\section{Experimental}

The experimental samples were prepared by Veeco GEN20 molecular beam epitaxy (MBE) system. The dopants were introduced from standard dopant cells, group III elements from SUMO cells and group V elements from valved cracker sources except nitrogen which was brought to the system using a radio-frequency plasma source.

We have studied two types of structures. The first sample type was nominally a single junction GaInNAs p-i-n type solar cell shown in Figure 1a. The structure comprised an unintentionally doped $\mathrm{Ga}_{1-x} \mathrm{In}_{x} \mathrm{~N}_{y} \mathrm{As}_{1-y}$ i-region, denoted as GaInNAs from here on, lattice matched to GaAs with a N-composition of $\mathrm{y}=0.02$ and In composition $\mathrm{x} \sim 2.7 \mathrm{y}$. The GaInNAs layer was placed between a $600 \mathrm{~nm}$ thick $\mathrm{n}-\mathrm{GaAs}$ layer and a $300 \mathrm{~nm}$ thick $\mathrm{p}$-GaAs layer and the whole structure was grown on an $\mathrm{n}-\mathrm{GaAs}(100)$ substrate. For modeling purposes and performance analysis, a set of p-i-n GaInNAs structures were grown with different thicknesses ranging from $0.1 \mu \mathrm{m}$ to $1.2 \mu \mathrm{m}$. The growth temperature was $440^{\circ} \mathrm{C}$ and the As/III beam equivalent

pressure (BEP) ratio for the growth of the GaInNAs layers was 10. Some samples were also subjected to rapid thermal annealing at $800^{\circ} \mathrm{C}$ for $300 \mathrm{~s}$ prior processing into solar cells.

The second sample type was an n-i-p grown on a p-GaAs(100) substrate. This structure (see Figure 1b) was comprised of a $100 \mathrm{~nm}$ thick p-GaInP back surface field layer grown onto a thin $\mathrm{p}-\mathrm{GaAs}$ buffer layer which was followed by a p-GaAs base layer and the GaInNAs i-region with $\mathrm{y}=0.035$ and corresponding $E_{g}=0.947 \mathrm{eV}$. The emitter layer was made of $100 \mathrm{~nm}$ thick $\mathrm{n}-\mathrm{GaAs}$ which was covered by a $20 \mathrm{~nm}$ thick AlInP window layer. The structure was finalized by growing a highly doped $\mathrm{n}^{+}-\mathrm{GaAs}$ contact layer. Beryllium was used as a p-type dopant and silicon was used as an n-type dopant. 


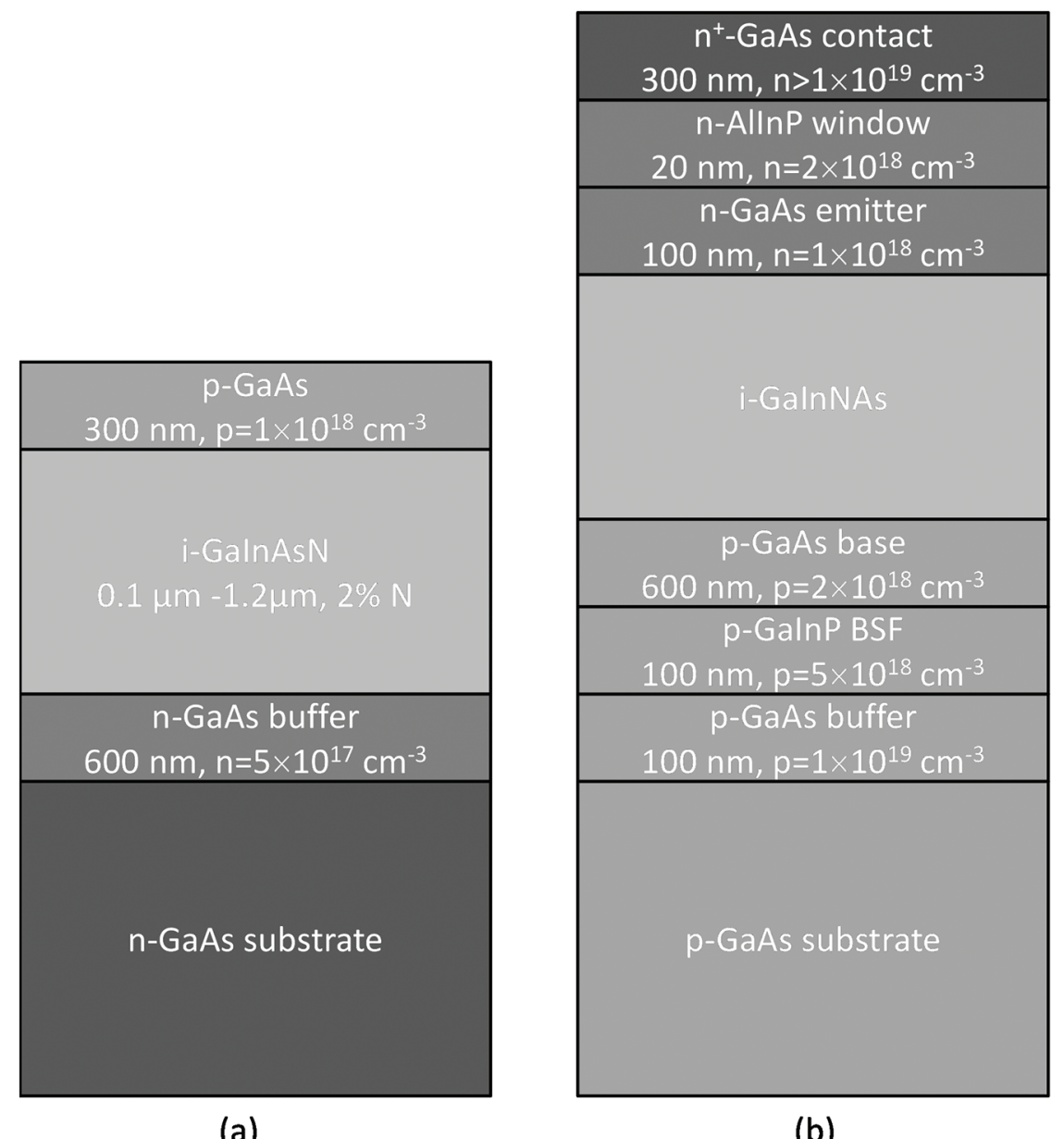

Figure 1 (a) The nominal layer structure for the single junction GaInNAs p-i-n solar cell. (b) The nominal layer structure for the single junction GaInNAs n-i-p solar cell.

Solar cells were processed using a shadow mask and e-beam metallization. The $\mathrm{p}-\mathrm{i}-\mathrm{n}$ structures were left uncoated while the $\mathrm{n}-\mathrm{i}-\mathrm{p}$ structures were also antireflection coated by e-beam evaporation of $\mathrm{TiO}_{2} / \mathrm{SiO}_{2}$ double layers to improve the characteristics of the cells.

Solar cells were characterized by $I-V$ measurements and external quantum efficiency (EQE) measurements. The $I-V$ measurements were performed using a $1000 \mathrm{~W}$ Oriel solar simulator tuned to AM0 spectrum for $\mathrm{p}-\mathrm{i}-\mathrm{n}$ structures and 
to AM1.5G spectrum for the n-i-p structures. The EQE measurements were performed using a system comprising of a QTH lamp, a computer-driven DK240 monochromator, long-pass and short-pass filters, an SR830 lock-in amplifier, current-to-voltage converter and a NIST-calibrated Ge photodiode.

The modelling was done using the open source simulation tool PC1D [9]. PC1D is 1-dimensional finite-element solver for photovoltaic devices which is well suited for crystalline semiconductor devices [10]. A set of materialspecific parameters are also needed in PC1D simulations. The parameters are not always known for all the novel materials and one complementary way to obtain the parameters is to use PC1D simulations in conjunction with the device measurements to deduce the right parameters via an iterative fitting procedure.

The initial material parameters used in the simulations are shown in Table 1. The values are either taken from literature or were based on measurements and earlier simulation work.

The simulations were performed using either AM0 or AM1.5G excitation spectrum. To simulate the response of the dilute nitride junction as a bottom sub-cell of a triple junction solar cell, a long-pass filter with a cut-off wavelength of $870 \mathrm{~nm}$ was used for p-i-n structures. The long-pass filter renders the action of the two top junctions grown above the GaInNAs junction in a triple junction solar cell.

The absorption coefficients of dilute nitride materials are not well known. For GaInNAs we used absorption coefficients measured previously by ellipsometry for materials with $E_{g}$ of $\sim 1 \mathrm{eV}$ [7]. The bandgap differences between different material compositions were taken into account by simply shifting the absorption edge according to the band edge location.

Table 1 The initial material parameters used for the $\mathrm{p}-\mathrm{i}-\mathrm{n}$ and n-i-p solar cell PC1D models

\begin{tabular}{lll}
\hline Parameter & GaAs & i-GaInNAs \\
\hline & & $0.947(\sim 3.5 \% \mathrm{~N})$ \\
Bandgap $(\mathrm{eV})$ & $1.424[12]$ & $1.13(2 \% \mathrm{~N}$, non-annealed $)$ \\
& & $1.17(2 \% \mathrm{~N}$, annealed $)$ \\
Electron affinity $(\mathrm{eV})$ & $4.07[13]$ & 4 \\
& & $2.80 \times 10^{10}(\sim 3.5 \% \mathrm{~N})$ \\
Intrinsic carrier conc. $\left(\mathrm{cm}^{-3}\right)$ & $2.07 \times 10^{6}$ & $1.45 \times 10^{9}(2 \% \mathrm{~N}$, non-annealed $)$ \\
& & $5.52 \times 10^{8}(2 \% \mathrm{~N}$, annealed $)$ \\
Electron mobility $\left(\mathrm{cm}^{2} / \mathrm{Vs}\right)$ & conc. dep. & conc. dep. \\
Hole mobility $\left(\mathrm{cm}^{2} / \mathrm{Vs}\right)$ & conc. dep. & conc. dep. \\
Carrier lifetime $(\mathrm{ns})$ & 100 & 0.9 (annealed) $[14,15]$ \\
& & 0.03 (non-annealed) [15] \\
\hline
\end{tabular}




\section{Results and Discussion}

\section{1 p-i-n Solar Cells}

The short-circuit current densities $\left(J_{s c}\right)$ and open-circuit voltages $\left(V_{o c}\right)$ deduced from the $I-V$ measurements for the non-annealed and annealed GaInNAs p-i-n solar cells with $2 \% \mathrm{~N}$ are shown in Figure 2 as a function of GaInNAs thickness. The best fits of the simulations for each of the samples are also included. Several observations can be made from the graphs. (i) For non-annealed samples the $J_{s c}$ increases for thicker GaInNAs layers at least until $1.2 \mu \mathrm{m}$ where it finally levels off. (ii) For annealed samples a different behavior is seen; an optimum thickness exists for the $J_{s c}$ at $\sim 700 \mathrm{~nm}$ after which $J_{s c}$ starts to decrease. (iii) Another observation is that the $V_{o c}$ of the nonannealed samples decreases with increasing the thickness of GaInNAs, while, (iv) the $V_{o c}$ of the annealed samples is rapidly increased from $0.37 \mathrm{~V}$ to $\sim 0.55 \mathrm{~V}$ when GaInNAs thicknesses increases from $0.1 \mu \mathrm{m}$ to $0.3 \mu \mathrm{m}$, respectively. Similar increase of $V_{o c}$ was also observed for samples which experienced even longer annealing (not discussed here for brevity). (v) Moreover, annealing almost doubles the $V_{o c}$ compared to the non-annealed samples. (vi) For the thickest sample, the $V_{o c}$ after annealing is decreased compared to thinner samples.
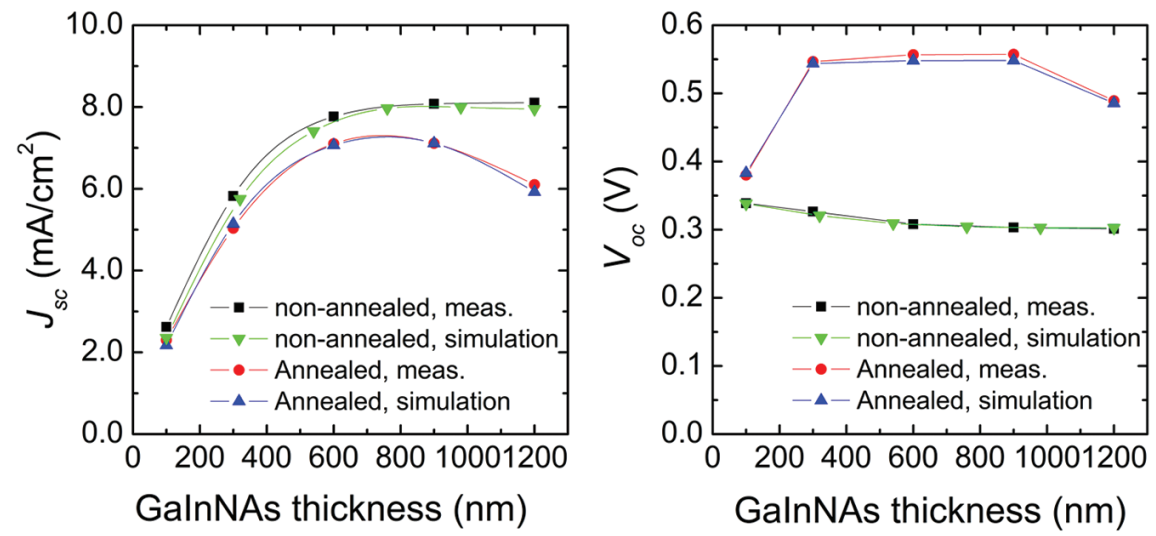

Figure 2 Measured and simulated (a) $J_{s c}$ and (b) $V_{o c}$ for non-annealed and annealed GaInNAs p-i-n solar cells with $2 \% \mathrm{~N}$ grown on $\mathrm{n}-\mathrm{GaAs}$ with different GaInNAs thicknesses. Measurements were done at room temperature and with AM0 spectrum with a $870 \mathrm{~nm}$ longpass filter inserted between the light source and the sample. The measured $J_{s c}$ and $V_{o c}$ data for the non-annealed samples are the same as in [7]. 


\section{A. Tukiainen et al.}

The simulation model assumes that the differences in $J_{s c}$ and $V_{o c}$ between annealed and non-annealed samples arise from several simultaneous changes in GaInNAs material parameters. The main changes that were needed to reproduce the measured $(I-V)$ characteristics are related to carrier lifetimes, doping type, carrier mobilities and doping profiles.

The GaInNAs layers in non-annealed samples were deemed to have ntype conductivity and the doping level in the model was set to $2 \times 10^{15} \mathrm{~cm}^{-3}$. Furthermore, very short carrier lifetimes of 33 ps for electrons and 87 ps for holes and surface recombination rate of $10^{6} 1 / \mathrm{cm}$ were required for the best fit [7]. The carrier mobilities used for the non-annealed samples were $417 \mathrm{~cm}^{2} / \mathrm{Vs}$ for electrons and $90 \mathrm{~cm}^{2} / \mathrm{Vs}$ for holes. The minority carrier diffusion length in GaInNAs deduced from the simulations was $\sim 125 \mathrm{~nm}$. This value is clearly larger than what was previously measured for $3 \mu \mathrm{m}$ thick undoped GaInNAs bulk layers grown on semi-insulating GaAs substrates [16].

For the annealed samples a very different set of parameters are needed to reproduce the measured $I-V$ characteristics. First of all, the lifetimes are drastically increased upon annealing; about tenfold increase of the carrier lifetime was needed in the model for almost all annealed samples. Interestingly, the conductivity type of GaInNAs had to be changed from n-type to p-type to account for the increased $V_{o c}$ and the behaviour of $J_{s c}$ with increasing GaInNAs thickness.

The doping type change was confirmed qualitatively by performing Kelvin probe force microscopy (KPFM) on the sample with $900 \mathrm{~nm}$ thick GaInNAs layer. Figure 3 shows the KPFM potential profiles measured across the cross-sections of the non-annealed and annealed p-i-n junctions. In the nonannealed sample the potential drop is associated with the interface between the GaInNAs and the top p-GaAs while for the annealed sample the potential drop is shifted to the interface between the GaInNAs layer and the n-GaAs layer. This directly indicates a movement of the pn-junction location and that the conductivity type of the GaInNAs layer must have changed its character upon annealing. Conductivity type changes in GaInNAs have also been seen by other authors in thermally annealed MOCVD-grown GaInNAs [17, 18] and in MBE-grown GaInNAs [19].

Based on the simulations, the base p-type doping was $1.5 \times 10^{15} \mathrm{~cm}^{2}$ but non-uniform profiles of p-type dopants were needed to fully explain the measured results. For holes, a GaInNAs thickness dependent diffusion depth factor variable was needed in the model and the peak p-doping variable was set to be the same as the doping level of the p-GaAs layer above the GaInNAs layer $\left(2 \times 10^{18} \mathrm{~cm}^{-3}\right)$ although in real case any diffusion from $\mathrm{p}-\mathrm{GaAs}$ would 


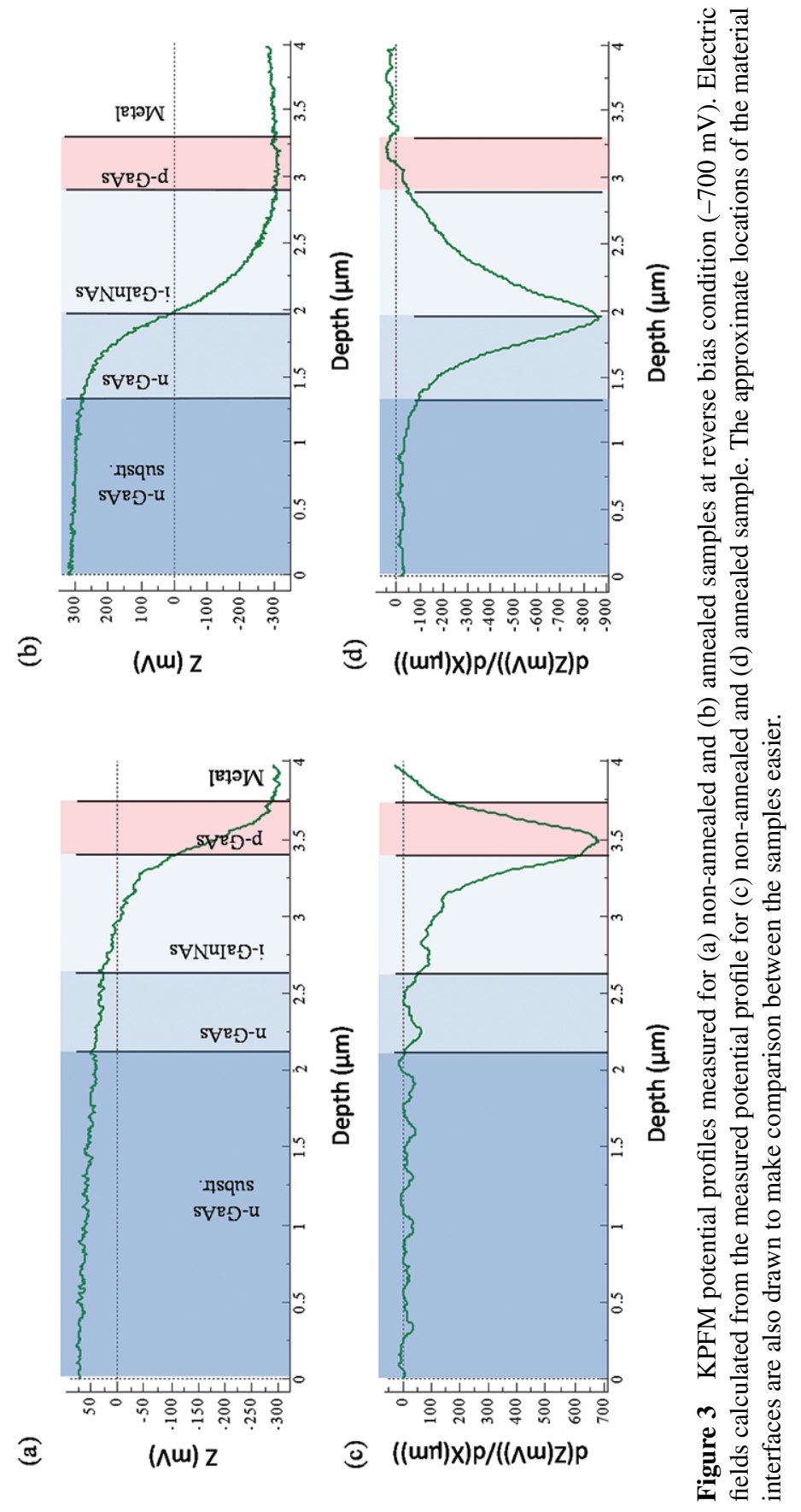


reduce the concentration on the other side of the interface. To illustrate the differences between the dopant profiles, the simulated diffusion profiles for non-annealed and annealed samples with $1200 \mathrm{~nm}$ GaInNAs are compared in Figure 4.

The depth factors for the annealed samples are shown in Figure 5 as a function of GaInNAs thickness. The thicker the GaInNAs layer is made, the larger depth factor is needed to fit simulations to the experimental results. It

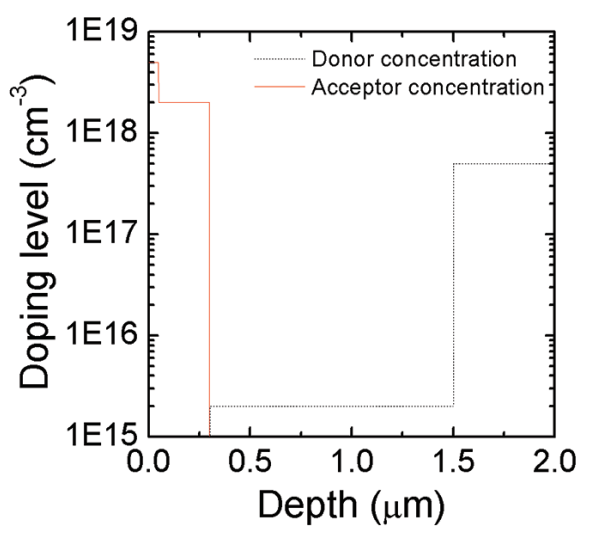

(a)

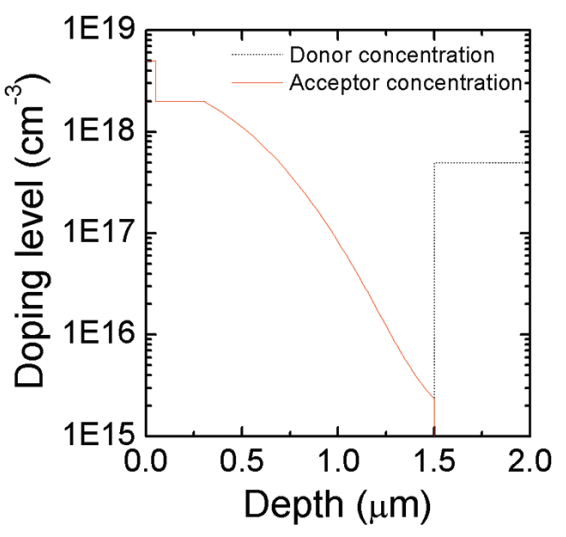

(b)

Figure 4 Simulated dopant concentrations for the GaInNAs p-i-n devices. (a) Non-annealed and (b) annealed sample with $1200 \mathrm{~nm}$ thick GaInNAs layer.

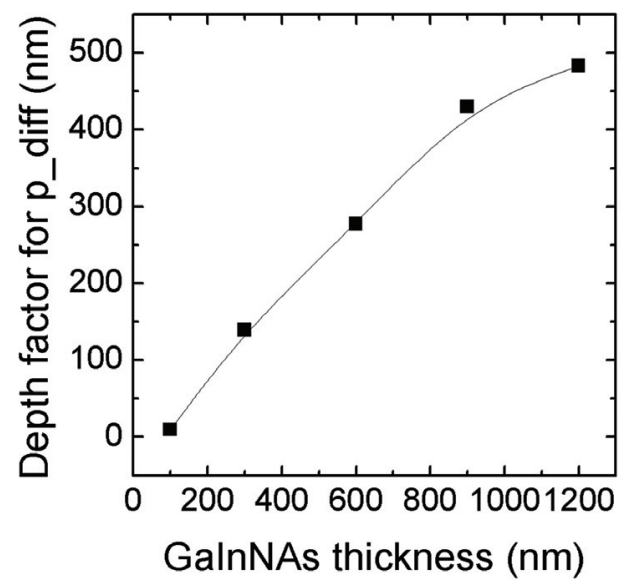

Figure 5 The p-dopant diffusion depth factor versus GaInNAs thickness in annealed samples. 
was also necessary to use doping concentration dependent carrier mobilities in the model. This allowed obtaining closely matched values for the measured and simulated $J_{s c}$ and $V_{o c}$.

The electron and hole lifetimes of non-annealed and annealed samples extracted from the model are listed in Table 2. For non-annealed samples a good fit is obtained when an electron lifetime of 33 ps and a hole lifetime of $80 \mathrm{ps}$ are used. The hole lifetime is slightly smaller than in [7] due to tuned carrier mobilities. The carrier lifetimes below 100 ps are well in line with time-resolved photoluminescence (TRPL) measurements on non-annealed GaInNAs samples with $2 \% \mathrm{~N}$ [15]. The lifetimes for the annealed samples are also well in the same range as the measured TRPL lifetimes for similar samples [15].

When the $J_{s c}$ values of non-annealed and annealed samples are compared, a striking fact is that $J_{s c}$ values are smaller for annealed samples, even though the carrier lifetimes are drastically increased. The reduced $J_{s c}$ in annealed solar cells can be explained by the fact that the junction position moves towards the $\mathrm{n}$-GaAs as a result of conductivity type change and the p-dopant profile across the GaInNAs. As a consequence, the position of the depletion region and therefore the electric field profile across the GaInNAs layer is altered. The simulated electric field distributions in non-annealed and annealed samples are shown in Figure 6. The electric field in the non-annealed sample extends from the interface between the i-GaInNAs and the p-GaAs at $0.3 \mu \mathrm{m}$ to about $0.9 \mu \mathrm{m}$, while for the annealed sample the electric field in that region is very small. However, as a consequence of the moved junction, the electric field of the annealed sample peaks at the location close to the interface between the i-GaInNAs and the n-GaAs, which is well in line with the KPFM measurements. This indicates that, the majority of photocarriers are generated in a volume without a significant electric field and this limits the carrier collection efficiency. When the changes in the carrier mobility due to increased p-doping upon annealing are combined with changes in the electric field profile, the result is reduced $J_{s c}$ in the annealed samples when compared

Table 2 The electron and hole lifetimes deduced from the simulations for non-annealed and annealed samples with different thicknesses

\begin{tabular}{lccccc}
\hline GaInNAs Thickness $(\mathrm{nm})$ & 100 & 300 & 600 & 900 & 1200 \\
\hline$\tau_{n}$ (ns) (non-annealed) & 0.033 & 0.033 & 0.033 & 0.033 & 0.033 \\
$\tau_{p}$ (ns) (non-annealed) & 0.080 & 0.080 & 0.080 & 0.080 & 0.080 \\
$\tau_{n}$ (ns) (annealed) & 0.04 & 0.69 & 0.8 & 0.9 & 0.58 \\
$\tau_{p}$ (ns) (annealed) & 0.04 & 0.69 & 0.8 & 0.9 & 0.46 \\
\hline
\end{tabular}




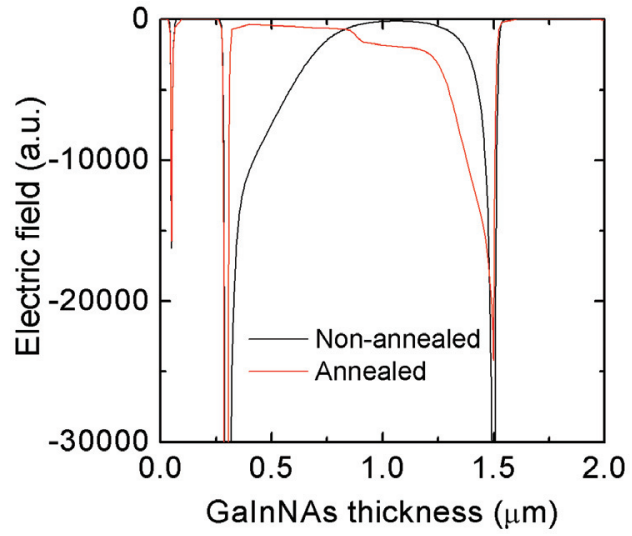

Figure 6 Simulated electric field distribution across the GaInNAs layer in non-annealed and annealed samples with $1200 \mathrm{~nm}$ thick GaInNAs.

to their non-annealed counterparts, and eventually, decreased $J_{s c}$ for thick GaInNAs layers.

The increase of the $V_{o c}$ upon annealing can be explained in the light of the model by two main factors: first, the lifetime increases, which also increases the $J_{s c}$. Secondly, the diffusion type of concentration profile of p-type dopants overcomes the base doping level almost throughout the GaInNAs layer and its effect on $V_{o c}$ can be understood through the relation $V_{o c}=\frac{k T}{q} \ln \frac{\left(N_{a}+\triangle n\right) \triangle n}{n_{i}^{2}}$, where $k$ is the Boltzmann constant, $T$ is absolute temperature, $N_{a}$ is the acceptor concentration, $\Delta n$ is the excess carrier concentration, and $n_{i}$ is the intrinsic carrier concentration [20]. The relation indicates that higher doping level leads to higher $V_{o c}$ values.

The p-type dopant profile in annealed GaInNAs may originate from dopant diffusion from the p-GaAs, but most likely at least part of the profile is caused by defects specific to GaInNAs. Also, the amount of dopants in the p-GaAs is not enough to supply for a diffusion profile needed to explain the $I-V$ results and simultaneously provide high doping levels in the p-GaAs layers. Therefore, the conclusion is that the p-doping profile has to be at least partly induced by a non-uniform transformation of $n$-GaInNAs to p-GaInNAs in a way that the p-doping concentration increases towards the p-GaAs. The doping profile differences between samples with different GaInNAs thicknesses could arise from combination of different defect populations of GaInNAs formed during the MBE growth and post-growth annealing. However, since the $I-V$ 
results prior to annealing can be simulated with a good accuracy using fixed doping level and lifetime, any defects playing a role here should be electrically inactive prior to post-growth thermal annealing. It is also known that beryllium diffusion in GaAs pn-junctions can be affected by the internal electric field [21]. In our case the internal electric field reduces when GaInNAs layer thickness increases. Therefore, thicker layers may experience different dopant diffusion during thermal annealing when compared to thinner layers, which in turn could lead to the observed differences in the doping profiles. An alternative model for the doping profiles of annealed samples can also be constructed to reproduce the observed $I-V$ characteristics. If the doping profile of GaInNAs were assumed to be flat, i.e., the p-doping would be kept constant across the layer, a conductivity type transformation would be still needed to explain the experimental results but for such a model clearly higher carrier lifetime values, than those ones presented in Table 2, would be needed. Figure 7 shows the simulated contour maps of $J_{s c}$ (red lines) and $V_{o c}$ (black lines) for the flat doping model. The crossing points of the thick lines indicate the value closest to the measured value for each sample. The sample with $100 \mathrm{~nm}$ GaInNAs is not shown because no clear crossing point was observed to match the measured $J_{s c}$ and $V_{o c}$.

For the flat doping profile model it becomes clear that the carrier lifetime mostly affects the $V_{o c}$ and the doping concentration affects both $V_{o c}$ and $J_{s c}$. The carrier lifetime and doping concentrations deduced from Figure 7 are shown in Figure 8 as a function of GaInNAs thickness. The results indicate that the p-doping concentration of the annealed GaInNAs layer reduces as a function of layer thickness. This model can also explain the reduced $J_{s c}$ for the annealed samples by the changes in the electric field profile as a consequence of n-to-p transformation.

It is however improbable that the samples would have flat doping profiles with dopant concentrations changing stepwise from one GaInNAs thickness to another. Also, there exists another factor that does not support the flat doping model for annealed samples. It is related to long carrier lifetimes needed for matching the simulated $J_{s c}$ and $V_{o c}$ to measured ones. Such long lifetimes contradict with the measured TRPL lifetimes [14, 15] for our annealed GaInNAs. Therefore, a more probable scenario is that the carrier concentration is increased in GaInNAs towards the p-GaAs interface as in our initial model. This is also supported to some level by capacitance-voltage measurements performed on GaInNAs n-i-p solar cell structures grown with similar As/III BEP ratios [22]. 


\section{A. Tukiainen et al.}
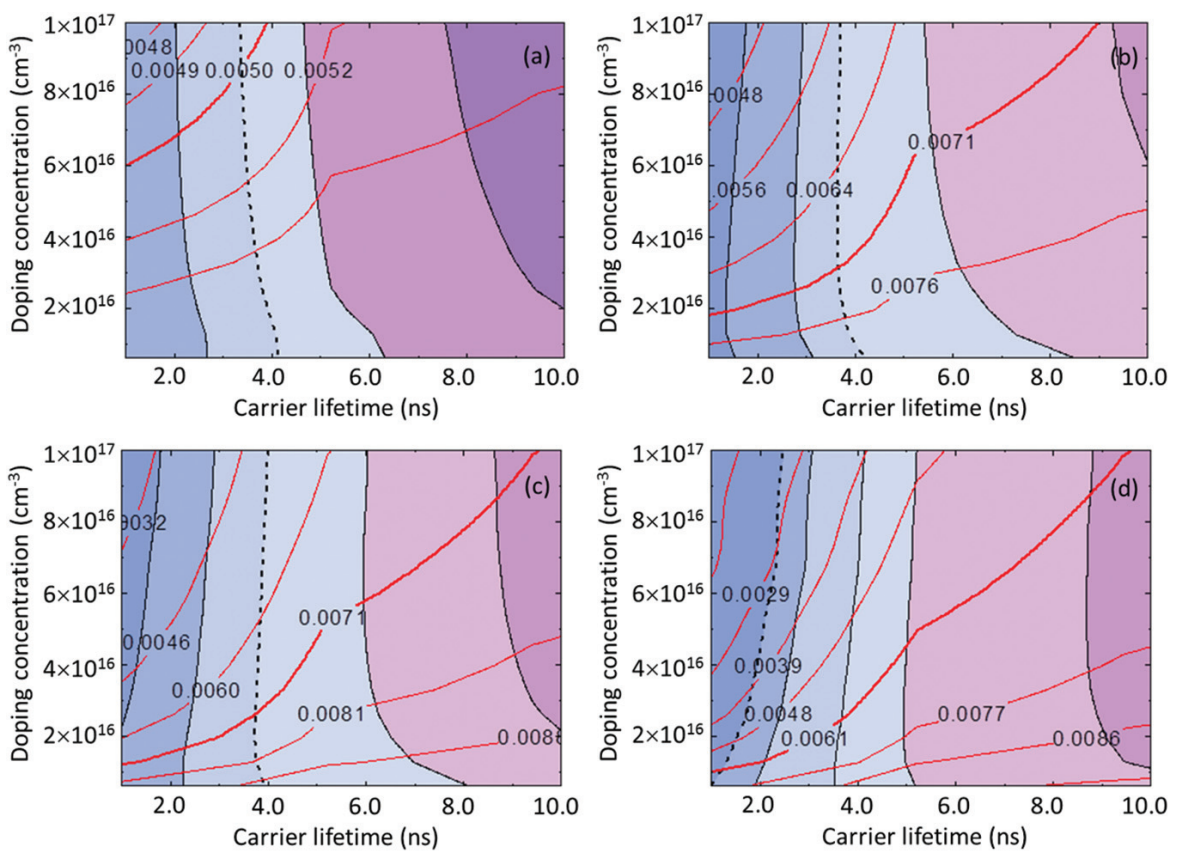

Figure 7 Simulated contour maps of $J_{s c}$ (red solid lines) and $V_{o c}$ (black lines) as a function of doping concentration and carrier lifetime overlaid for the samples with GaInNAs thicknesses of (a) $300 \mathrm{~nm}$, (b) $600 \mathrm{~nm}$, (c) $900 \mathrm{~nm}$, and (d) $1200 \mathrm{~nm}$. The crossing points of the thick red solid lines and thick black dotted lines indicate the values corresponding to the experimentally measured $J_{s c}$ and $V_{o c}$.

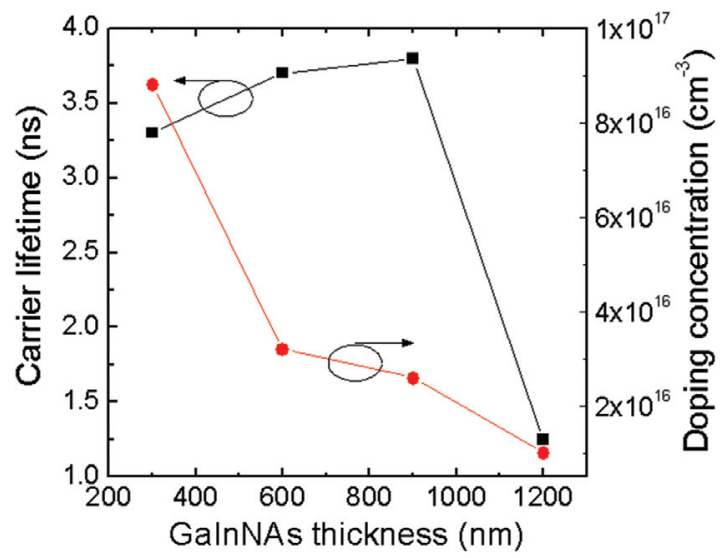

Figure 8 Carrier lifetime and doping concentrations as a function of GaInNAs thickness deduced from the flat doping model. 


\section{2 n-i-p Solar Cells}

Usually, the multi-junction solar cells are fabricated on p-type substrates in n-on-p configuration because lightly doped p-base layers provide higher minority carrier mobilities than n-type layers and thus a good collection efficiency for the minority carriers is achieved. Therefore, we have also simulated and fabricated dilute nitride solar cells in n-i-p configuration.

The nominal sample structure was presented in Figure 1b. Because the $\mathrm{n}$-i-p structures consist of more than 5 different material layers, we can take into account in PC1D simulations only those layers that matter most. Here, the basic simulation structure consists of the n-AlInP window, the n-GaAs emitter, i-GaInNAs, the p-GaAs base, and the p-GaInP BSF layer. These layers form the essential parts of the structure for the simulation. Some resistive losses take place at the semiconductor interfaces and also in the substrate but these effects are deemed to me minor. The material parameters used for the GaInP and AlInP layers are shown in Table 3. The mobilities for AlInP and GaInP were based on Hall measurements. Previously, we have performed PC1D simulations on similar structure type to obtain the $I-V$ and EQE characteristics of n-i-p structures with a rather good success [7]. The simulation of the annealed n-i-p GaInNAs single junction solar cells differs from GaInNAs $\mathrm{p}$-i-n simulations discussed above in that no diffusion profiles were used for the carrier concentration profile.

Here we present measured and simulated EQEs of three GaInNAs n-i-p solar cells. The GaInNAs layers had different background doping concentrations due to different As/III ratios [21]. The simulation model is very similar to the p-i-n model, but here the bandgap of the material was set to $0.947 \mathrm{eV}$, intrinsic carrier concentration was calculated to be $2.80 \times 10^{10} \mathrm{~cm}^{-3}$, and the absorption edge was tuned to fit the band edge. The average doping concentrations obtained from the $C-V$ measurements were used as input for the simulation. The measured and simulated EQEs are shown in Figure 9a. A rather good fit to the measured EQE was obtained only when the carrier lifetime was treated as a free parameter. The lifetimes leading to the best

Table 3 Materials parameters for GaInP and AlInP

\begin{tabular}{lll}
\hline Parameter & $\mathrm{n}$-AlInP & $\mathrm{p}$-GaInP \\
\hline Bandgap $(\mathrm{eV})$ & $2.35[11]$ & 1.89 \\
Electron affinity $(\mathrm{eV})$ & $3.78[13]$ & $4.01[13]$ \\
Electron mobility $\left(\mathrm{cm}^{2} / \mathrm{Vs}\right)$ & 129 & 173 \\
Hole mobility $\left(\mathrm{cm}^{2} / \mathrm{Vs}\right)$ & 21 & 41 \\
Carrier lifetime $(\mathrm{ns})$ & 2 & 5 \\
\hline
\end{tabular}



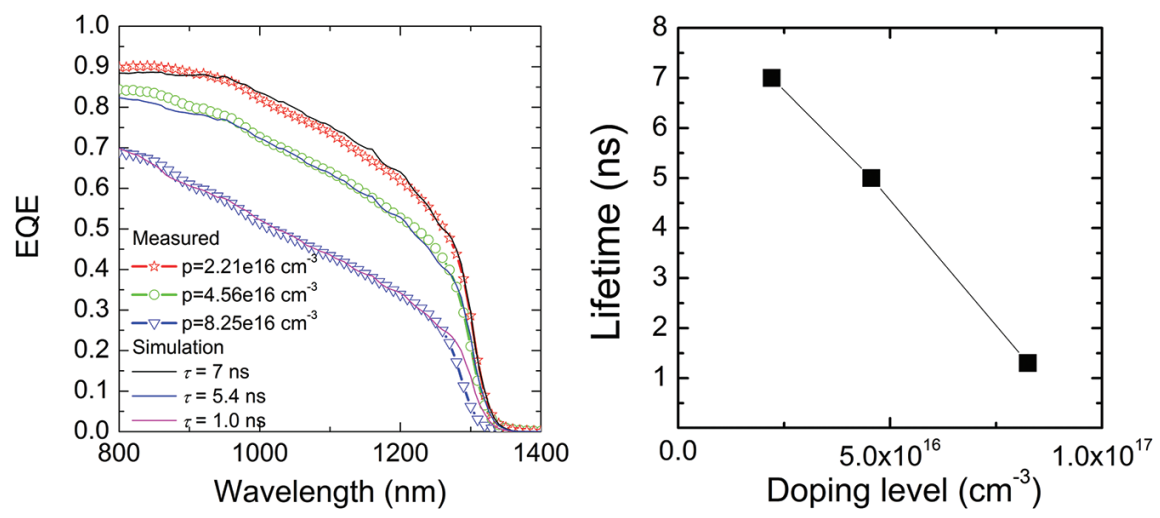

Figure 9 (a) EQE measurements and fitted simulations on a set of GaInAsN n-i-p structures with different p-doping levels. (b) The dependence of the fitted lifetimes on the doping level.

fit for each background doping concentration are shown in Figure 9b. The lifetime was found to increase linearly with decreasing p-type background concentration.

The flat doping model might not be the best model for these n-i-p solar cells even though it seems to work very well. The reason is the same as discussed for the p-i-n devices - in the samples with higher background carrier concentration it seems that the doping level is not constant as was shown in [22]. And if a non-uniform p-type doping concentration were assumed for these samples, it would probably lead to shorter extracted lifetime components but the similar trend as shown in Figure $9 \mathrm{~b}$ should still be expected. This means that when using low As/III ratios one can on the other hand reduce the amount of nonradiative recombination that is detrimental to GaInNAs solar cells and also reduce the carrier concentration that is beneficial for the solar cells. This way, EQE values exceeding 0.9 are possible even for GaInNAs solar cells without using $\mathrm{Sb}$ as surfactant.

\section{Conclusions}

We have constructed a 1D PC1D model for $\mathrm{p}-\mathrm{i}-\mathrm{n}$ and $\mathrm{n}-\mathrm{i}-\mathrm{p}$ GaInNAs solar cells grown by molecular beam epitaxy. For non-annealed p-i-n solar cells very good match to the measured $J_{s c}$ and $V_{o c}$ were obtained using a flat doping model while for annealed samples a non-uniform doping profile and carrier lifetimes approaching $1 \mathrm{~ns}$ were needed. Annealing was found to transform the conductivity of GaInNAs from n-type to p-type, which was verified by 
KPFM measurements. The information obtained from the simulations can also qualitatively explain why the non-annealed solar cells have inferior characteristics when compared to their annealed counterparts. For n-i-p solar cells the model suggests that the lower doping induced by lower As/III BEP ratio is associated with increase in the carrier lifetime.

\section{Acknowledgement}

The authors would like to thank Mr. Pekka Malinen, Ms. Wenxin Zhang and Mr. Joel Salmi for their valuable technical support in fabrication of the solar cell structures and components. For the financial support, we would like to thank Finnish Funding Agency for Technology and Innovation-TEKES (projects 40120/09, Solar III-V and 40239/12, NextSolar).

\section{References}

[1] Aho, A., Isoaho, R., Tukiainen, A., Polojärvi, V., Aho, T., Raappana, M., et al. (2015). "Temperature coefficients for GaInP/GaAs/GaInNAsSb solar cells," in AIP Conference Proceedings, 1679:050001, doi: $10.1063 / 1.4931522$

[2] Green, M. A., Emery, K., Hishikawa, Y., Warta, W., and Dunlop, E. D. (2013). Solar cell efficiency tables (version 41). Prog. Photovolt. Res. Appl. 21, 1-11.

[3] Friedman, D. J., Geisz, J. F., Kurtz, S. R., and Olson, J. M. (1998). 1-eV Solar cells with GaInNAs active layer. J. Cryst. Growth 195, 409-415.

[4] Jackrel, D. B., Bank, S. R., Yuen, H. B., Wistey, M. A., Harris, J. S. Jr., Ptak, A. J., et al. (2007). Dilute nitride GaInNAs and GaInNAsSb solar cells by molecular beam epitaxy. J. Appl. Phys. 101:114916.

[5] Vijaya, G. K., Alemu, A., and Freundlich, A. (2010). "Modeling of $1 \mathrm{eV}$ dilute nitride multi-quantum well solar cell," in Proceedings of the 35th IEEE Photovoltaic Specialists Conference (PVSC), 000380-000384. doi: 10.1109/PVSC.2010.5616832

[6] Aho, A., Tukiainen, A., Polojärvi, V., and Guina, M. (2014). Performance assessment of multijunction solar cells incorporating GaInNAsSb. Nanoscale Res. Lett. 9, 1-7.

[7] Tukiainen, A., Aho, A., Polojärvi, V., and Guina, M. (2014). "Modeling of MBE-Grown GaInNAs Solar Cells," in Proceedings of the Digest of the 10th European Space Power Conference ESPC 2014, Noordwijkerhout, $719,1-4$. 
[8] Aho, A., Polojärvi, V., Korpijärvi, V., Salmi, J., Tukiainen, A., Laukkanen P., et al. (2014). Composition dependent growth dynamics in molecular beam epitaxy of GaInNAs solar cells. Solar Energy Mater. Solar Cells $124,150-158$.

[9] Clugston, D. A., and Basore, P. A., (1997). "PC1D VERSION 5: 32BIT SOLAR CELL MODELING ON PERSONAL COMPUTERS," in Proceedings of the 26th IEEE Photovoltaic Specialists Conference.

[10] Basore, P. A. and Clugston, D. A. (1996). "PC1D Version 4 for windows: from analysis to design," in Proceedings of the 25th IEEE Photovoltaic Specialists Conference, Washington, 377-381.

[11] Vurgaftman, I., Meyer, J. R. and Ram-Mohan, L. R. (2001). Band parameters for III-V compound semiconductors and their alloys. J. Appl. Phys. $89,5815-5875$.

[12] Sze, S. M., (1981). Physics of Semiconductor Devices, 2nd Edn. New York, NY: John Wiley \& Sons.

[13] Gudovskikh, A. S., Kaluzhniy, N. A., Lantratov, V. M., Mintairov, S. A., Shvarts, M. Z., and Andreev, V. M., (2008). Numerical modelling of GaInP solar cells with AlInP and AlGaAs windows. Thin Solid Films 516, 6739-6743.

[14] Aho, A., Tukiainen, A., Polojärvi, V., Korpijärvi, V., Gubanov, A., Salmi, J., et al. (2011). "Lattice matched dilute nitride materials for III-V high-efficiency multi-junction solar cells: growth parameter optimization in molecular beam epitaxy," in Proceedings of the 26th European Photovoltaic Solar Energy Conference and Exhibition, Hamburg, Germany.

[15] Gubanov, A., Polojärvi, V., Aho, A., Tukiainen, A., Tkachenko, N. V., and Guina, M. (2014). Dynamics of time-resolved photoluminescence in GaInNAs and GaNAsSb solar cells. Nanoscale Res. Lett. 9:80. doi: 10.1186/1556-276X-9-80

[16] Lebedeva, N., Repo, P., Yli-Koski, M., Savin, H., Aho, A., Tukiainen, A., et al. (2011). "Experimentally defined electronic properties of InGaAsN: input for solar cell simulations," in Proceedings of the 26th European Photovoltaic Solar Energy Conference and Exhibition 2011.

[17] Kurtz, S., Geisz, J. F., Friedman, D. J., Metzger, W. K., King, R. R., and Karam, N. H. (2004). Annealing-induced-type conversion of GaInNAs. J. Appl. Phys. 95:2505, doi: 10.1063/1.1643775

[18] Kurtz, S., King, R., Law, D., Ptak, A., Geisz, J., and Karam, N. (2013). "Effects of in situ Annealing on GaInNAs Solar Cells," in Proceedings 
of the IEEE 39th Photovoltaic Specialists Conference (PVSC), doi: 10.1109/PVSC.2013.6744887

[19] Langer, F., Perl, S., Höfling, S., and Kamp, M. (2015). p- to n-type conductivity transition in $1.0 \mathrm{eV}$ GaInNAs solar cells controlled by the V/III Ratio. Appl. Phys. Lett. 106:063905, doi: 10.1063/1.4909507

[20] Sinton, R. A., and Cuevas, A. (1996). Contactless determination of current-voltage characteristics and minority-carrier lifetimes in semiconductors from quasi-steady-state photoconductance data. Appl. Phys. Lett. 69, 2510-2512. doi: 10.1063/1.117723

[21] Enquist, P., Wicks, G. W., and Eastman, L. F. (1985). Anomalous redistribution of beryllium in GaAs grown by molecular beam epitaxy. J. Appl. Phys. 58, 4130-4134. doi: 10.1063/1.335543

[22] Polojärvi, V., Aho, A., Tukiainen, A., Raappana, M., Aho, T., Schramm, A., et al. (2016). Influence of As/group-III flux ratio on defects formation and photovoltaic performance of GaInNAs solar cells. Solar Energy Mater. Solar Cells 149, 213-220. doi: 10.1016/j.solmat.2016.01.024

\section{Biographies}

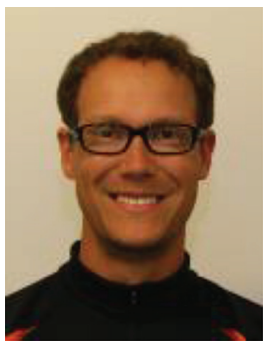

A. Tukiainen received the M.Sc. degree in Electrical Engineering in 2000 and the D.Sc. (Tech.) degree in Science and Engineering (semiconductor physics) from Tampere University of Technology, Finland, in 2009. He is currently working as a Senior Research Fellow at Optoelectronics Research Centre, Tampere University of Technology, Tampere, Finland. Currently, his research focuses on development of high-efficiency III-V multijunction solar cells and related compound semiconductor technology and device simulations. Previously, he has been involved in epitaxy and characterization of semiconductor lasers, quantum dots and sub-micron structures. He has hand-on 
expertise on several electrical, optical and structural characterization methods. He has authored and co-authored more than 70 peer reviewed scientific articles.

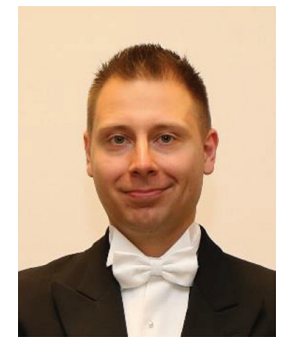

A. Aho received the M.Sc. degree in 2009 and the D.Sc. (Tech.) degree in semiconductor physics from Tampere University of Technology, Tampere, Finland, in 2015. He is currently working as a researcher at Optoelectronics Research Centre, Tampere University of Technology, Tampere, Finland. His research focuses on III-V multijunction solar cell materials, especially on the growth physics of molecular beam epitaxy and growth process development of dilute nitride solar cells. Prior to solar cell and the doctoral thesis work, his research topics have also included epitaxy and characterization of III-V laser materials based on quantum wells and quantum dots.

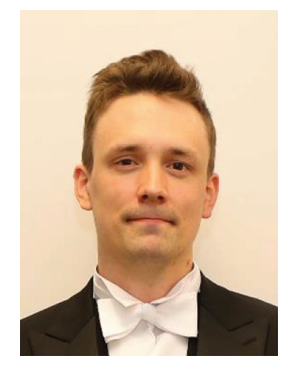

V. Polojärvi received the M.Sc. degree in semiconductor physics in 2009 and the D.Sc. (Tech.) degree in semiconductor physics from Tampere University of Technology, Tampere, Finland, in 2016. He is currently working as a researcher at Optoelectronics Research Centre, Tampere University of Technology, Tampere, Finland. His research focuses on process development and characterization of III-V multijunction solar cells and solar cell materials. 
$\mathrm{He}$ has also expertise on processing and characterization of other III-V semiconductor devices, materials, surfaces, interfaces and nanostructures.

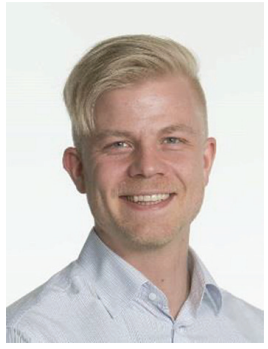

R. Ahorinta received the M.Sc. degree in semiconductor physics from Tampere University of Technology, Tampere, Finland, in 2010. At Tampere University of Technology, his research topics included material and device characterization and especially spectroscopic ellipsometry of III-V materials and scanning probe microscopy based surface characterization techniques including Kelvin Probe Force Microscopy (KPFM). In 2011 he moved to industry and since then he has worked with various companies including Labtronic Oy and Mallincroft Pharmaceuticals.

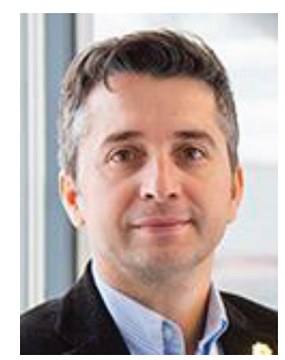

M. Guina is the Head of the III-V Optoelectronics Group at Tampere University of Technology, Finland. He conducts scientific work in the field of molecular beam epitaxy of novel optoelectronic heterostructures and devices. His current projects are concerned with the epitaxy of highly mismatched III-V compounds, epitaxy of nanostructures, the development of high power semiconductor lasers (VECSELs and MOPAs), and the development of ultrahigh efficiency multijunction solar cells based on GaInNAsSb-alloys. He has published more than 150 journal papers, several book chapters, holds 


\section{A. Tukiainen et al.}

4 international patents, has several position of trust in COST Actions and scientific boards, and has given numerous invited talks at major optoelectronics conferences. Prof. Guina is the Director of the International Summer School "New Frontiers in Optical Technologies", which he established in 2001. He has an outstanding track record in leading large scale research projects extending from basic science to technology transfer; he is the recipient of 2016 ERC Advanced Grant "AMETIST" and co-founder of two start-ups. Prof. Guina's group webpage: http://www.tut.fi/orc/semicon 